\title{
An Advance Security Technique Challenges to Government in Wireless Sensor Network for Health
}

\author{
S.Mohapatra ${ }^{1}$, G.S. Rout ${ }^{2}$, S.S.Behera ${ }^{3}$, A.K.Mohanty ${ }^{4}$ \\ ${ }^{1}$ Asst. Professor, School of Electronics, Campus-12, KIIT University \\ E-mail: 'sraddhanjalimohapatra@gmail.com, ${ }^{2}$ routg66@yahoo.com,3swaroop.swastik30@gmail.com, \\ 4abhayamhnty@yahoo.co.in
}

\begin{abstract}
Changes in the Internet, World Wide Web technologies and services lead to new developments in the way of E-Government efforts to provide better services to citizens and businesses due to governments handles their internal operations. One of the revolutionary developments comes from adoption of wireless technologies in government related activities. E-Governance is an influential tool for bringing challenges to the government process in the developing world. Mainly, E-Governance operates at the cross roads between information and communication Technology (ICT) and Government Processes (GP). An effective EGovernance model is that systematically applied to a specific healthcare industry sector. As E-Governance is involved in global technology transfers data from the original project context into a different sociocultural environment. The Health Services to the public is a collaborative program between the clinical medical programs and the Department of Health Systems; Management \& Policy at the Public Health System and Health Educational System are an interdisciplinary program that evaluates organization, delivery and reimbursement in health care to public. It is response to the Government access the information from all sectors and will give them valuable suggestions. The need to collect data about people's physical, physiological, psychological, cognitive, and behavioral processes in spaces ranging from urban and rural area. In this paper we present the the recent availability of the technologies that enable this data collection, storing, retrieving and security system for the information through wireless sensor networks for healthcare. In this paper, we outline prototype systems spanning application domains from physiological and activity monitoring the urban and rural hospitals and behavioral works and emphasize ongoing treatment challenges to the patient day to day and that information will be available in centrally. Then any moments the higher authorities can able to verify.
\end{abstract}

Keywords: Healthcare monitoring; medical information systems; wireless sensor network, wavelet technology.

\section{INTRODUCTION}

In this era of intensifying regulatory requirements and growing volumes of information, striking a balance between the risks of unmanaged information with business value is a challenge. EGovernance is the application of Information and Communication Technology (ICT) for delivering government services, exchange of information communication transactions, integration of various stand-alone systems and services between Government-to-Citizens (G2C), Government-toBusiness (G2B), and Government-to-Government $(\mathrm{G} 2 \mathrm{G})$ as well as back office processes and interactions within the entire government frame work [1]. Through the E-Governance, the government services will be made available to the citizens in a convenient, efficient and transparent manner. Generally four basic models are availableGovernment to Customer (Citizen), Government to Employees, Government to Government and Government to Business [2]. "E-government" is the use of the ICTs in public administrationscombined with organizational change and new skills- to improve public services and democratic processes and to strengthen support to public". The governance of ICTs requires most probably a substantial increase in regulation and policymaking capabilities, with all the expertise and opinion-shaping processes among the various social 
stakeholders of these concerns. So, the perspective of the E-Governance is "the use of the technologies that both help governing and have to be governed [3]. Wireless data offerings are now evolving to suit consumers due to the simple reason that the Internet has become an everyday tool and users demand data mobility. Currently, wireless data represents about 15 to $20 \%$ of all air time. While success has been concentrated in vertical markets such as public safety, health care, educations, administrations, panchayata raj and transportation, the horizontal market (i.e., consumers) for wireless data is growing. The Internet is system which has changed user expectations of what data access means. The ability to retrieve information via the Internet has been "an amplifier of demand" for wireless data application. The word "electronic" in the term EGovernance implies technology driven governance. E-Governance is the application of Information and Communication Technology (ICT) for delivering government services, exchange of information communication transactions, integration of various stand-alone systems and services between Government-to-Citizens (G2C), Government-toBusiness (G2B), and Government-to-Government $(\mathrm{G} 2 \mathrm{G})$ as well as back office processes and interactions within the entire government frame work. India is a Sovereign Socialist Secular Democratic Republic with a Parliamentary form of government which is federal in structure with unitary features. There is a Council of Ministers with the Prime Minster as its head to advice the President which is the constitutional head of the country. Similarly, in states a Council of Ministers with the Chief Minister as its head advises the Governor. This section provides insight of Indian governance and administration at the Central, state as well as local level. Information about the Constitution of India, Parliament and Legislature, Union administration, state, district and local administration is given. Health care should be within the reach of every citizen. For providing basic health facilities to all citizens, government has introduced and implemented various health schemes and programmes. This section provides information pertaining to health programmes, policies, schemes, forms etc. for specific beneficiaries who include women, children, senior citizen, etc. Details of Union and state government agencies, departments, organizations, research institutions, hospitals are also available. The National E-Governance Plan of Indian Government seeks to lay the foundation and provide the impetus for long-term growth of E-Governance within the country. This section provides information on relation of the right governance and institutional mechanisms, setting up the core infrastructure and policies and implementation of a number of Mission Mode Projects at the Center, State, District, Block and integrated service levels. India is a Sovereign Socialist Secular Democratic Republic with a Parliamentary form of government which is federal in structure with unitary features. There is a Council of Ministers with the Prime Minster as its head to advice the President which is the constitutional head of the country. Similarly, in states a Council of Ministers with the Chief Minister as its head advise the Governor. This section provides insight of Indian governance and administration at the Central, state as well as local level. Information about the Constitution of India, Parliament and Legislature, Union administration, state, district and local administration is given. Healthcare is always a big concern, since it involves the quality of life a given individual can have. It is always better to prevent an illness than to treat it, so individual monitoring is required as a periodic activity. The aging population of developed countries present a growing slice of government's budget, and presents new challenges to healthcare systems, namely with elderly people living on independent senior housing [4]. Accurate and relevant, storage, durable, retrieval, distributed, analytics, better decision making, efficient allocation of resources, targeted healthcare interventions, identification of patient and community needs, preventive health education and changes in health-oriented behavior, effective disease management and better quality care. The links in the E-Governance value chain can be mutually reinforcing and create information flows. This type of Healthcare work flow well known as the paradigm of preventive health care. Egovernance is the application of information \& communication technologies to transform the efficiency, effectiveness, transparency and accountability of informational \& transactional exchanges with in government, between govt. \& govt. agencies of National, State, Municipal \& Local levels, citizen \& businesses, and to empower citizens through access \& use of information. E Governance has proved beneficial in many ways by the different initiatives of the government in different states of India whether it's a big city or a small town. 


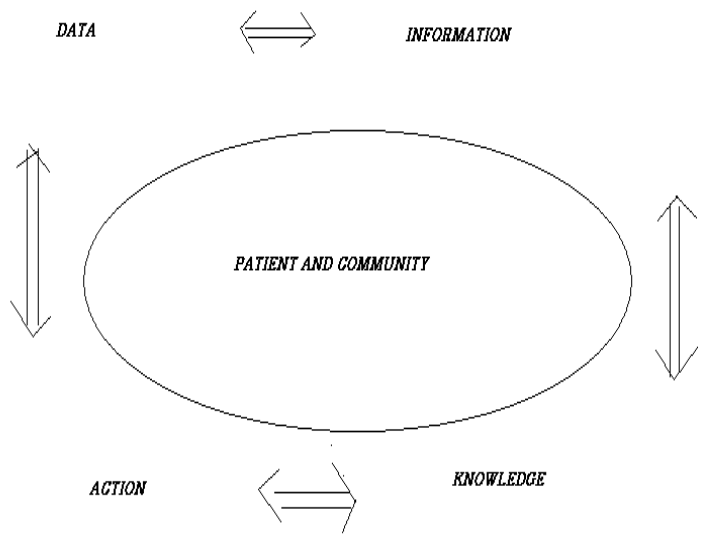

Fig. 1. Paradigm of preventive healthcare

\section{LITERATURE SURVEY}

Many of the aforementioned requirements have not yet been adequately addressed by the sensor network community. The chief reason is that most sensor network applications have very different data, communication, and lifetime requirements. The researchers [5] have described some representative applications in the healthcare domain and also described the challenges in wireless sensor networks due to the required level of trustworthiness. They have described that wireless sensor networks for healthcare potential was trustworthiness and privacy and the ability to deploy large-scale systems to operated in unsupervised environments. The researcher [6] had described an effective E-governance model that systematically applied successfully in transcultural E-governance project, drawing empirical evidence through its application to a specific healthcare industry sector. The researchers [7] have analyzed the using wearable and non-wearable sensor devices for tracking and monitoring the healthcare perspective with or without the consent of the particular person.

The researchers [8] described about the E-series multifunction data acquisition cards were used for the acquisition of biomedical signals and the appropriate software NI-DAQ (National Instruments-Data Acquisition). They have also analyzed the advanced techniques available on the computer were becoming invaluable to the practicing physician. They [9] have proposed and used large variety of methods for featuring high percentages of correct detection ECG for reading and saving in a file and the filtering, squaring, integrating, applying the moving window can be accurately done using Pan-Tompkins algorithm.
The researchers [10] analyzed the true potential of $\mathrm{m}$-Governance in the Indian scene where the EGovernance services can be provided through wireless and mobile technologies. They have also riveted on $\mathrm{M}$-Health to $\mathrm{m}$-Governance projects implemented in other countries, and examine the M-PESA mobile commerce project in Kenya. The author [11] emphasized the little change on actual current health status of E-governance (ICT) in large hospitals, awareness and accessibility of Egovernance to the patients. The survey conducted in hospitals involved the patient's responses and responses from the Healthcare Professionals. Unlike traditional data collection applications such as environmental monitoring [12-14], medical deployments were characterized by nodes with varying data rates and few opportunities in network aggregation. In addition, medical sensor networks were less concerned with maximizing individual node lifetimes, since it is acceptable to recharge devices or change batteries on a relatively frequent basis. As a result, many of the significant advances in communication models [15-16], time synchronization [17-18], and energy management [19] should be revaluated given these new requirements. Most of the projects were concerned with developing wearable medical sensors [20-22], while others have developed infrastructures for monitoring individual patients during daily activity, at home [23-25] or at a hospital. The SMART [26], AID-N [27], and WiiSARD [28] teams were among several funded through a US National Library of Medicine effort to develop new technologies for disaster management. The AID-N group had designed WSN for healthcare using WSNs and the SMART team has developed a mote-based EKG [29]. The WiiSARD group has developed a prototype pulse ox meter based on an 802.11equipped PDA, but its size and power requirements make it impractical for real medical use. The WiiSARD and SMART designs call for a central server to collect and distribute all sensor data, and approach with obvious reliability and scalability considerations. A wireless patch-type physiological monitoring micro system was proposed by $\mathrm{Ke}$ and Yang [30] in which the skin temperature, ECG signals, and respiration rate are measured and shown by computer information centre. In this section, we propose a wireless physiological signal monitoring system which integrates a SoC platform, Bluetooth wireless, and Internet technologies to home-care application to collect the heart rate, ECG, and body temperature into nursing center respectively. In 2006, Lin and et al. [31] proposed a wireless physiological monitoring system named RTWPMS to monitor the 
physiological signals of aged patients via wireless communication channel and wired local area network. Body temperature, blood pressure, and heart rate signals are collected and then stored in the computer of a network management centre in Lin's system. Researchers, both within the GEI program [32-36) have also recognized the utility of such sensing in making measurements for longitudinal studies ranging from the scale of individuals to large populations. Curtis and et al. [37] have used geo-positioning to locate the patient and caregiver in their project called SMART (Scalable Medical Alert Response Technology). Meingast and et al. [38] have raised similar questions regarding patient privacy as:

i. Who can have permission to own the data;

ii. What type of medical data, how much, and where the data should be collected;

iii. Who can have permission to inspect the medical data; and

iv. To whom should medical data be revealed to without the patient's consent?

Over use of ICT have also limitations and hazards [39] free information will shift the power balance between doctors and patients [40] with not differentiate right and wrong information in specific context [41]. So computer guided self treatment may be hazardous with [42] greater empowerment of patients for higher responsibility regarding self treatment. It was essential need of special legislation on data privacy, security, authorization etc [43]. The researchers [44] analyzed the nature of ubiquitous devices made wireless networks the easiest solution for their interconnection with the rapid growth of several wireless systems like wireless ad hoc networks, wireless sensor networks etc. They have proposed a framework for rural development by providing various E-services to the rural areas with the help of wireless ad hoc and sensor networks to collect the accurate information in time. The author's [45] had discussed that geographical, social, \& economical disparities were the biggest barriers of the country for full-fledged E-Governance. They have also discussed about the illiteracy, lack of infrastructure, security and privacy of personal and financial data's of country. The author [46] analyzed the scope for application of ICT at Primary, Secondary and Tertiary healthcare Institutions for effective computerization of hospitals and Medical Colleges supported by Networking and Video Conferencing to increase efficiency, quality of Patient care and patient satisfaction.
The number of weaknesses in medical healthcare pointed out by different researchers has been taken into account and a noble solution is proposed in the present work. This paper articulates about wavelet technique related technologies keeping in view of various needs in medical healthcare. The proposed process will allow medical healthcare whether all associated accessories related to healthcare will be inspected by higher authorities later on with a specialization of information technology skill.

This paper proposed a wavelet technique solution to store large amount errorless information for higher authorities to observe the correct information's. In this way higher authorities will capable to inspected healthcare in proper manner. In this paper, an efficient wavelet based algorithm has been developed to facilitate an online, interactive and fruitful verification by higher authorities and able to give some direction to them. Healthcare work flow is a well known paradigm of preventive health care for the people. E-governance is the application of information \& communication technologies to transform the efficiency, effectiveness, transparency and accountability of informational \& transactional exchanges with in government, between govt. to govt. agencies of National, State, Municipal \& Local levels, citizen $\&$ businesses, and to empower citizens through access \& use of information. E Governance has proved beneficial in many ways by the different initiatives of the government in different states of India whether it's a big city or a small town.

\section{WSN CHALLENGES IN HEALTHCARE}

Management is a goal oriented activity inside the organization but governance is made from outside. So governance and management are not same. It can be simplified by ICT application. ICT can enable health related information in the web, create PPP model, help customer contact, allocate patient to different level of health care, provide electronic forum for patient interaction and build Eprescription system. It is high time to explore how doctors and IT personnel can work together to reduce health care cost, deliver high quality service, properly management the healthcare and cover rural as well as urban masses. The advance technology in low-power networked systems and medical sensors are witnessed in the emergence of wireless sensor networks (WSNs) in healthcare which drastically improving and expanding the quality of care across a wide variety of settings and for different segments of the population. A wireless networked sensing is to provide active assistance 
S. Mohapatra et al. / International Journal of Computer Networks and Communications Security, 1 (4), September 2013

and guidance to patients coping with declining sensory and motor capabilities. New types of intelligent assistive devices that make use of information about the patient's physiological and physical state from sensors built in the device, worn or even implanted on the user's person, and embedded in the surroundings. The general hospitals in the country is the heart of the citizen of the villages / blocks / districts / states by providing efficient and quality health services through IT application with improved patient care and effective administration and control. Traditionally, health monitoring is performed on a periodic check basis, where the patient must remember its symptoms; the doctor performs some check and formulates a diagnostic, then monitors patient progress along the treatment, if possible etc are done by ICT. Healthcare for the patient is done properly or not is investigated by higher authority through of wireless sensor networks.

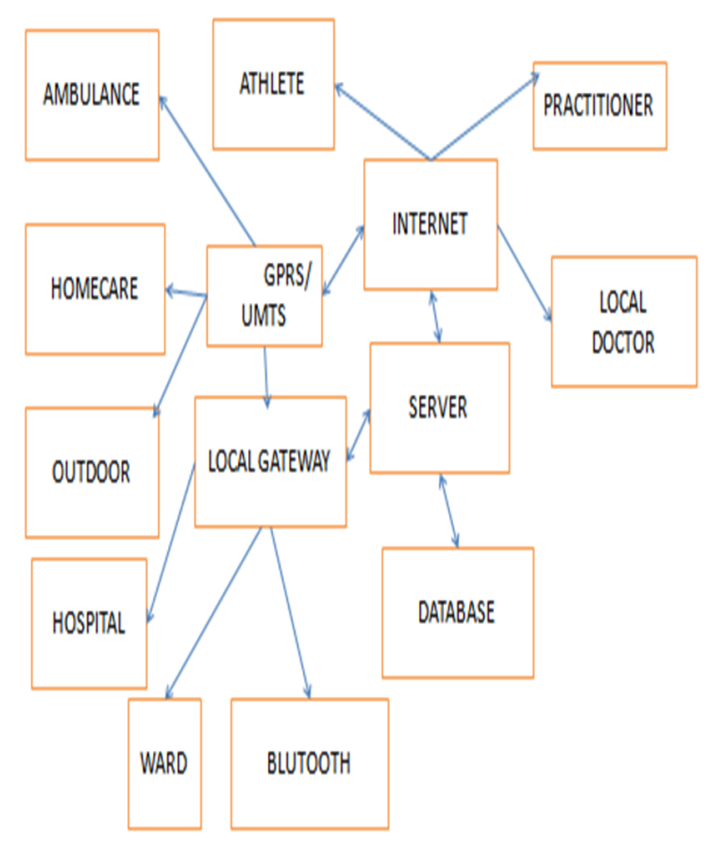

Fig. 2. Healthcare using different wireless sensor networks

These challenges reach above and beyond the resource limitations that all WSNs face in terms of limited network capacity, processing and memory constraints, as well as scarce energy reserves. Specifically, unlike applications in other domains, healthcare applications impose stringent requirements on system reliability, quality of service, and particularly privacy and security. In this paper, we have to expand on these challenges and provide examples of initial attempts to confront them. The vital sign monitoring, it is possible to achieve highly reliable data delivery over multi hop wireless networks deployed in clinical environments to overcome energy and bandwidth limitations by intelligent preprocessing of measurements collected by high data rate medical applications such as motion analysis for Parkinson's disease; an analysis of privacy and security challenges and potential solutions in assisted living environments

\section{SECURITY TECHNOLOGY FOR E- HEALTHCARE}

Challenging Healthcare solutions will be integrated into image technology process. In the long term, Healthcare solutions and services are also likely to be integrated into electronic appliances, machines and information interfaces. Images are required for substantial storage and transmission resources. So advantage of image compression technique is required to reduce these data. This paper covers some back ground of wavelet analysis, data compression and how the wavelets have been used for image compression. The threshold is the extremely important influence of compression results to suggest the wavelet technique. As the image compression [47] is that much important one, for that purpose, we will consider an image and assume that the image in a matrix form. As we have to consider the image in matrix of pixel values. In order to compress the image, redundancies [48] must be exploited. For example such exploitations those areas where there is a little change or no change between the pixels are considered as same. Therefore the images having large area of uniform color will have large redundancies and conversely images that have frequent and large changes in color will be redundant and hard to compress. The analysis can be used to divide the information of image in to approximation and detail sub signals show the original trend of pixel values. Three detail sub signals show the vertical, horizontal and diagonal details or changing image. If these details are very small then they can be set to zero without significantly changes in the image. If these values are in the threshold, than they can set to zero [49]. Since those values are less that the threshold values then they will become to zero. In this way, if we get a lot of zeros, then we can say that the image is compressed extremely. After the image compression [50-51] is over that the aim is to get or retrieve the image. The process of retrieving 
decomposes the image from compression is called're-strained'. If the energy restrained is $100 \%$ that the process is called loss less energy re-strained and image is re-constructed exactly. If the image is not decompose totally, than the type of compression is called lose de-compression.

The important technical issues are discussed here.

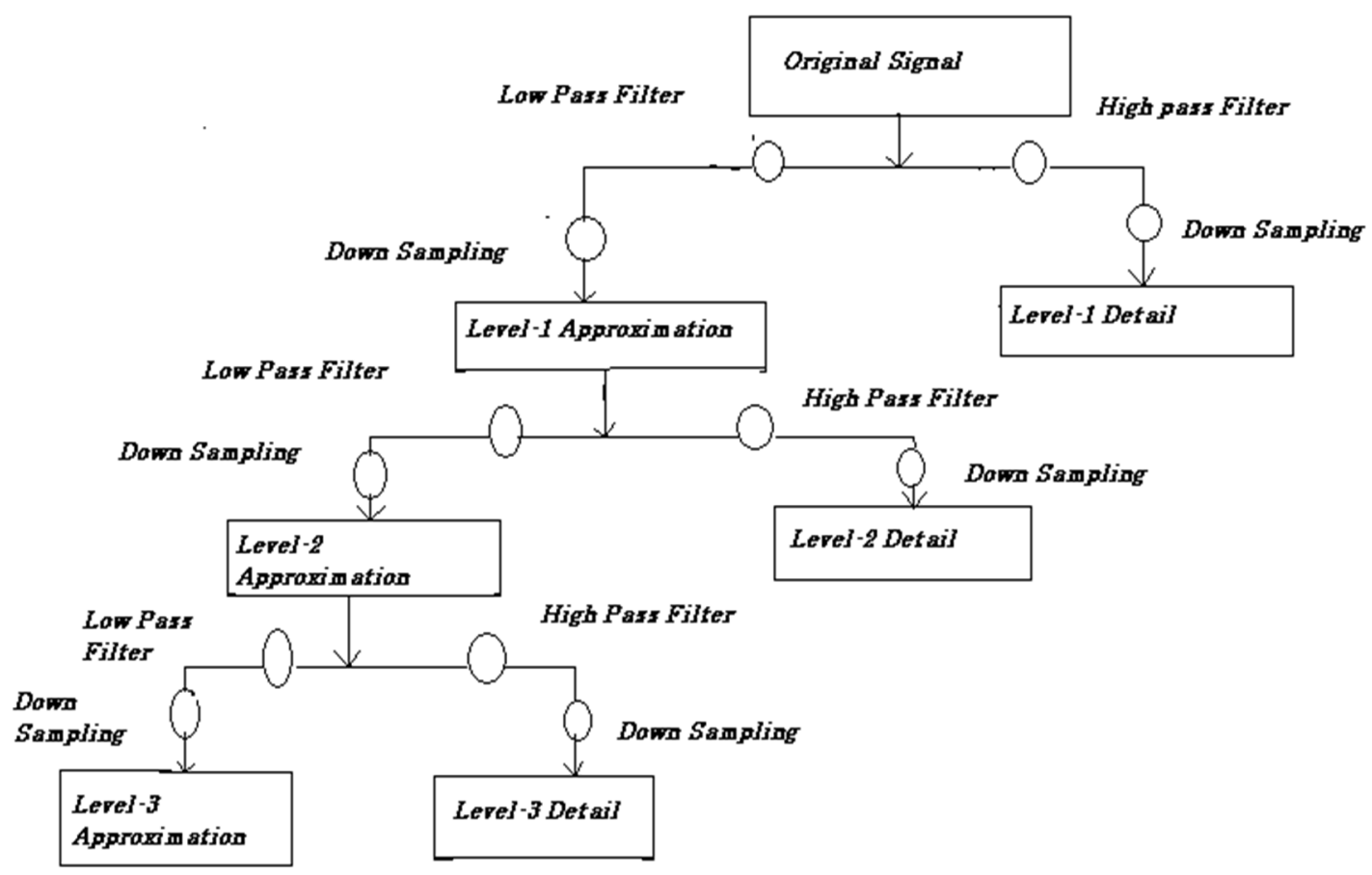

Fig. 3. (a)

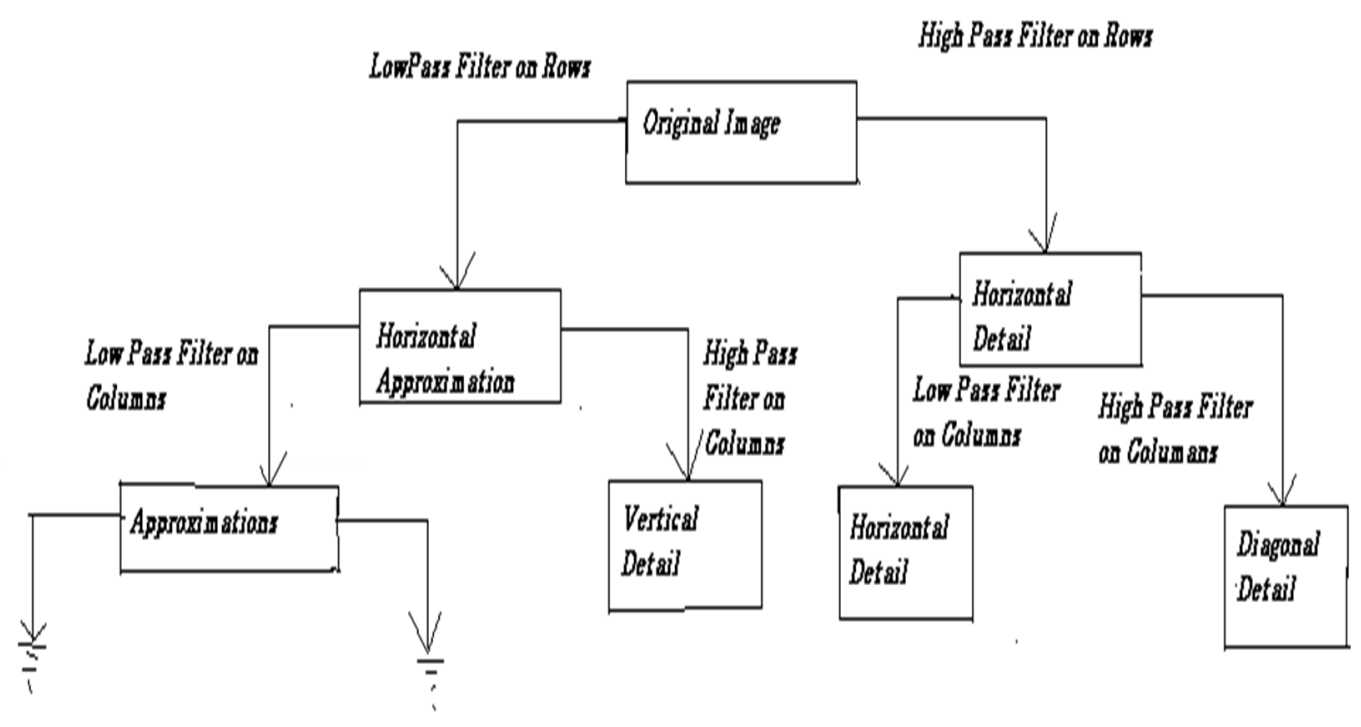

Fig. 3. (b) 
Fig.3(a) \& 3(b) Working of Wavelet Technique by multi resolution analysis de-compressing and compressing respectively.

After Compression, the decompression technique is used to retrieve the information with accuracy and that can be achieved by the intelligent mechanism techniques. Among lot of techniques are available we are going for the particle swarm optimization technique. In this technique we will follow an algorithm [52] for retrieval the exact information. According to that algorithm, it will follow and accurate information can be retrieved easily. There are a number of challenges associated with the long term preservation of digital data. In this paper, we are going to describe how the future desired data are preserved in digital document system. Of most interest to us for this paper are the requirements of future end users of a preserved digital data document. It is crucial when implementing an archival system for the long term preservation of digital data, to consider the end user's needs with respect to the preserved digital document. Such considerations aid in determining exactly what information should be preserved along with the digital document and in what way and we cannot predict everything at the end user. But it may to want to do with a preserved digital document in the future. Which we can assume that they will expect, at least to have the ability to view or interact with the data in the same way as today's users. As such, it is critical that preserved documents can be rendered authentically on future computers. Moreover, the digital document should be interpretable and understandable to future end users as well as remaining usable. As more research, educational and cultural institutions come to realize the enormity and complexity of work required to store, preserve, and accurate large amounts of their unique digital information. More over many will turn to establishing cooperative partnerships for leveraging existing mass-storage capacity or utilizing 3rd party data duration service providers to help satisfy their needs for a redundant and secure digital preservation system.

\subsection{Searches the Exact Data}

For searching the desired data we have lot of algorithms, but among them they are not showing the exact data whatever we are required. For this purpose in this paper we are proposed a technique to search the data accurately with minimum time with without losing of information. That algorithm is the particle swarm optimization technique. By using this we can change the data from real format to binary format and it will search the desired information. Then it will show us the exact data within less time without lossing the information. PSO is a population-based optimization technique developed by Kennedy and Eberhart (1995) and Shi and Eberhart (1998) [53]. It is initialized with a population of random solutions. The algorithm searches for optima satisfying some performance index over generation. It uses the number of agents that constitutes a swarm moving around in the search space looking for best solution. The PSO technique can generate high quality of optimization solution within a short computation time and exhibits a more stable convergence characteristic than other optimization methods. The PSO contains' individual swarms called 'particles'. Each particle represents a possible solution to a problem with $d$-dimensions and its genotype consists $2 * d$ parameters. First $d$-parameters represent the 'particle positions' and next $d$-parameters represent velocity components. These parameters move with an adaptable velocity within the search space and retain its own memory with the best position it ever reached. The parameters get changed when moving from present iteration to the next iteration. At every iteration, the fitness function as a quality measure is calculated by using its position vector. Each particle keeps track of its own position, which is associated with the best fitness which has achieved so far. The best position obtained so far for particle $i$ keeps the track.

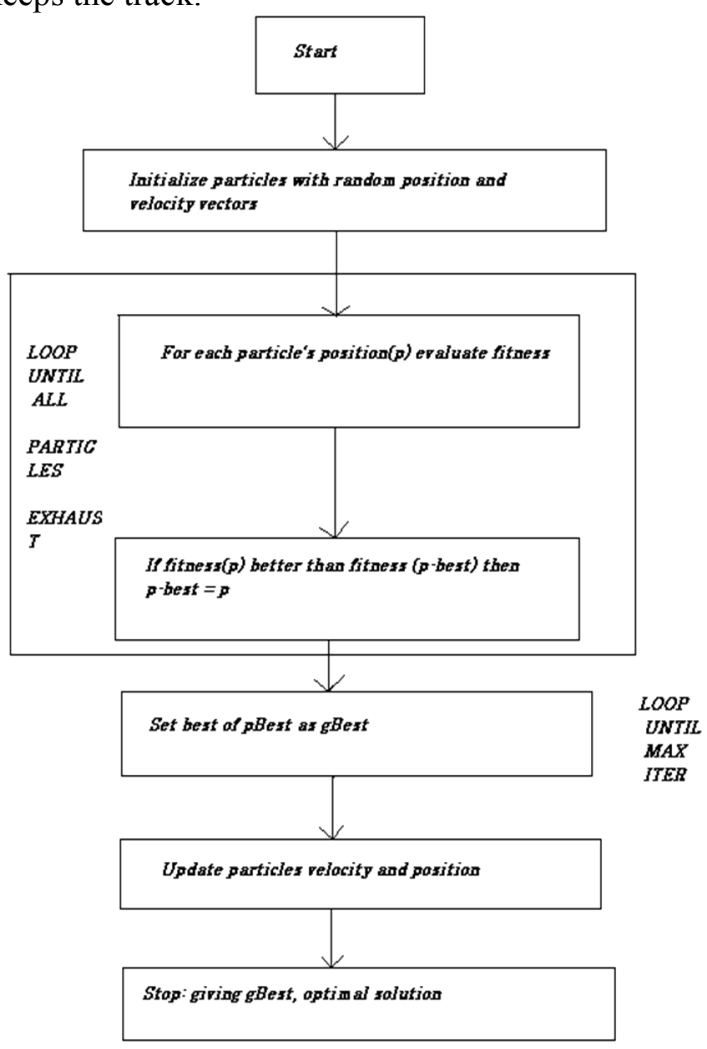

Fig. 4. Comments on the inertial weight factor 
A large inertia weight $(w)$ facilitates a global search while a small inertia weight facilitates a local search. By linearly decreasing the inertia weight from a relatively large value to a small value through the course of the PSO run gives the best PSO performance compared with fixed inertia weight settings.

\subsection{Simage Search Algorithm by Using Distributive Co-Operating Technique}

A distributed system is one in which the processors are less strongly connected. A typical distributed system consists of many independent computers in the same room, attached via network connections. Such an arrangement is often called a cluster [54, 55]. A distributed algorithm is an algorithm designed to run on computer Hardware constructed from interconnected processors. Distributed algorithms are used in many variety application areas of distributed computing, such as telecommunications, scientific computing, distributed information processing and real-time process control [56, 57]. Standard problems solved by distributed algorithm are included leader election, consensus, and distributed search, spanning tree generation, mutual exclusion \& resource allocation. Distributed algorithms are typically executed concurrently with separate parts of the algorithm being run simultaneously on independent processors \& having limited information about what the other parts of the algorithm are doing. One of the major challenges in developing and implementing distributed algorithm is successfully coordinating the independent part of the algorithm in the face of processor failure and unreliable communications links. The choice of appropriate distributed algorithm to solve a problem depends both on the characteristics of the problem and the system. The algorithm will run in such a manner that the probability or link wills not failure. The kind of inter-process communication can be performed with help of the level of timing synchronization between separate processors. The distributed object-oriented paradigm helps the designer to master the complexity of cooperative systems. To specify a distributed algorithm, we observe it from three points of view: the group of objects (a set of distributed entities involved in a distributed computation), objects (a local entity), and their methods (an action that can be performed). In our methodology we define an abstract machine specification as an equivalent state/transition model. A state is mainly characterized by its assertion definition. Such an assertion is first expressed using classical logic operators applied to methods on remote or local objects. We add other logic operators to include parallel and distributed features. They allow expressing knowledge and belief predicates. For the final implementation step these operators are realized by particular method calls. Finally a state predicate is verified if it takes a value in a defined set of possible values. A transition is associated with an action to be performed. In fact we use condition / action systems. An enabling condition for a transition is checked and, only if it is true, the corresponding action is executed. Refinement transforms step by step an abstract model (in the remaining of the paper we use invariably the terms specification and model) of a software system into an executable code. It must be emphasized that, by our different refinement steps, each model inherits the behavioral and knowledge aspects from higher levels. For instance, when a knowledge predicate is used in a group specification, the corresponding knowledge predicate will be found in the object specification level (for instance by the way of Boolean local variables). A distributed system is an interconnected collection of Autonomous process. Such as: Information exchange (WAN), resource sharing (LAN), Multicourse programming, Parallelization to increase performance etc. Replication is increase reliability and, modularity is improved to design the system easily. The configuration of a distributed algorithm is composed from the states as its processes and the messages in its channels. A transition is associated to an event at one of its processes. A process can perform internal, send and receive events. So a process is an internal or send event. An algorithm is centralized if there is exactly one initiator. A decentralized algorithm can have multiple initiators. To search any picture we have to use the Thumbnail of the Image as a query, because Thumbnail of any Images is parts of the picture regardless whatever the background. By using one universal Image search algorithm that can capable to represent the features of any multimedia data type for solving the problems. We will use the contents of the Picture as our index key which uses a K-Tree [58]. A directed graph, containing $2^{k}$ incoming nodes and one outgoing node have some benefits for the degree of $\mathrm{K}$ is affected by the complexity of the data-structure. For another data type we will reuse an algorithms particular feature. Secondly the Information's stored at the higher level of the tree are the lower amount of the feature to describe the global Information. On the other hand the higher Information and the features are stored at the lower level of the tree. Therefore the user's requirements can be adapted between the time and the accuracy by selecting appropriate level 
of the tree. Thirdly the features of K-Tree are independent, so the position of the nodes in the tree is same. The problem of inconsistent index structure occurs when a multiple-feature query comes. If the indices of different structures or different data types are processed individually, the database join operation is needed to merge results from each individual index and filters that do not comply with the temporal or spatial constraints. By using the K-Tree to search every feature altogether takes shorter computing time than using featuredependent structure to search on many indices individually, then merge all results and filters them with spatial constraints.

\subsection{The Generalized Retrieval Model}

The $k$-tree structure is used to retain location information and also a histogram is used to store the characteristics of each portion of the data that corresponds to a part of the tree. This generalized model is depicted in Figure III. First, either general mathematical models, or special methods, extract the feature of interest. Second, the domain of data type is reduced into a set and each item in the database is also mapped to the set. Third, virtual data values are added to data items, if necessary, to create such that each item will generate a balanced $k$-tree. A $k$-tree is built using histogram values for each feature.

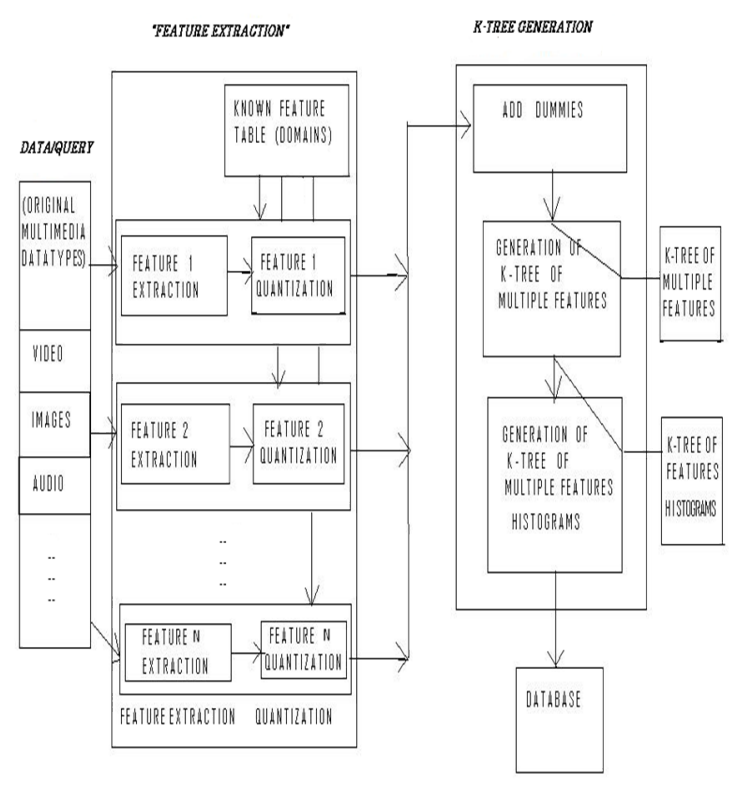

Fig. 5. Generalized Indexing/Retrieving Model

\section{BINARY PSO}

Binary PSO based multi-objective Rule Selection Algorithm to perform multi-objective rule selection; we have already extracted N classification rules in the rule discovery phase of classification rule mining. These $\mathrm{N}$ rules are used as candidate rules in the rule selection phase. Let $\mathrm{S}$ be a subset of the $\mathrm{N}$ candidate rules (i.e. $\mathrm{S}$ is a classifier). A binary string of length $\mathrm{N}$ represent $\mathrm{S}$, where " 1 " means the inclusion in $\mathrm{S}$ and " 0 " means the exclusion from $\mathrm{S}$ of the corresponding candidate rule. We use binary MOPSO to search for pare to optimal rule sets of the following threeobjective rule selection problem. Maximize f1(S) where $\mathrm{fl}(\mathrm{S})$ is the number of correctly Classified training patterns by S, Minimize $\mathrm{f} 2(\mathrm{~S})$ where $\mathrm{f} 2(\mathrm{~S})$ is the number of selected rules in S, Minimize f3(S) where $\mathrm{f3}(\mathrm{S})$ is the total number of antecedent condition over selected rules in S. The first objective is maximized while the second and third objectives are minimized.

The third objective can be viewed as the minimization of the total rule length since the number of antecedent condition of each rule is often reformed to as the rule length.

\section{ALGORITHM FOR PSO}

Step-1: Initialise the population POP: Randomly generate Npop binary strings (particles) of length $\mathrm{N}$ is (no.of candidate rules extracted in rule Extraction phase)

Step-2: Initialise the position of each particle: For $\mathrm{i}=1$ to Npop, $\mathrm{xt}(\mathrm{i})=\mathrm{pop}[\mathrm{i}]$

Step-3: Initialise the velocity of each particle: For $\mathrm{i}=1 \mu$ Npop, vt $[\mathrm{i}]=0 /$ initializing each velocity with single of 0 's /

Step-4: Initialise the $\mathrm{P}$ best of each particle: For $\mathrm{i}=1$ to Npop, PBEST[i] $=\mathrm{xt}[\mathrm{i}]$

Step-5: Evaluate the fitness of each particle /* compute $\quad \mathrm{fl}(\mathrm{s}), \quad \mathrm{f} 2(\mathrm{~s}) \quad \& \quad \mathrm{f3}(\mathrm{s})$

Step-6: Store the position of the particles that represent non-dominated vectors in the reposition REP.

Step-7: WHILE maximum number of cycles has not been reached DO

(a) Compute the best for each particle in the reposition REP applying k-method clustering technique on two objective criterions coverage and confidence. 
(b) Compute the speed of each particle using the following expression bit wise:

For $\mathrm{C}=1$ to $\mathrm{L}$

$\mathrm{vt}+1[\mathrm{i}][1]=\mathrm{vt}[\mathrm{i}][1]+\operatorname{Rand}()($ PBRST [i] [1]

$-x t[i][()]+$ Rand $(0)(G$ BEST [i] [1]-xt [i] [()]

$/ x$ Rand ( ) tables the values in the range (0.1)

(c) Update the new positions of the particles $\mathrm{xt}+1[\mathrm{i}]$ bit wise:

For $\mathrm{l}=1$ to $\mathrm{L}$

Calculate the threshold value

If $($ rand ()$<w)$ then $x t+1[i][1]=1$

else $x t+1[i][1]=0$

(d) Evaluate the fitness of each of the new particles in pop

(e) Update the p best of each particle

(f) Update the contents of reposition REP by inserting all the currently non-dominated particles into the reposition. Any dominated totaling from the reposition are eliminated in the process, since the size of the reposition is limited, wherever it gets full, a secondary criterions for refection known as crowding distance technique is applied. The final result of PSO-based multi objective rule selection (all the final non-dominated particle in the reporting) is not a single rule set but a number of non-dominated rule sets with respect to the three objectives in (7). This is the main characteristic feature of PSO-based multi-objective rule selection.

\section{ALGORITHM FOR PICTURE}

\subsection{The Virtual-Node (VN) in-picture search algorithm}

Case A) if query's tree aligns within the k-tree structure of data:

1. Find the distances between feature in root of the query tree and nodes of the data at level Li-1 nodes with solid-line link - of the stored item. If distances are equal to the distance between the query and their parents, the query could be found within those child nodes.

2. Repeat Case A) Recursively on this child node. If there is no distance at level Li- 1 close to the distance to the parent, the query is "not aligned". Follow Case B below.

Case B) if the query data falls in between two or more nodes:

1. If no node in $k$-tree can be a candidate, Virtual nodes (white nodes) between two nodes have to be generated from the parts of their child nodes.
2. Repeat the whole algorithm into a new tree; use the whole algorithm within the dashed box.

Case C) If height of query is equal to a node height:

1 Use histogram distance function to calculate the distance then

2 Return the distance and location.

Generalized Virtual-Node (GVN) in Picture Search Algorithm

Extended_Query=Add_Dummies (Query)

Feature_Of_Extended_Query

Feature_Extraction (Extended_Query)

VirtualNodeComparison

(Feature_Of_Extended_Query,

Feature_Of_Extended_Data, ROOT, distance,

Tentative Location)

IF (distance $<$ threshold) THEN BEGIN

Find "Query_Representative," the largest node in the k-tree of feature_Of_Query, where no parts of dummies are included.

Virtual Node Comparison (Query

Representative, Feature_Of_Extended_Data,

Tentative_Location, distance1,

Tentative_Location1)

IF (distance $1<$ threshold1) THEN BEGIN

Find the final distance by calculating the distance between the query and area of data where the beginning of the area is at Tentative_Location1.

Distance $=$ distance 1

Location $=$ Tentative_Location 1

RETURN

END

END

\section{CONCLUSION}

The essential components of Challenging Government, E-Governance for Healthcare solution is very important. We have proposed a solution for complete E-Governance of Government for Healthcare solution is used the efficient wavelet based technique for securing important informations. The Image search algorithm, generalized retrieval model along with Binary PSO based Search Algorithms are also used to achieve the efficient, compressed \& secured searching procedure. E-Governance is the future; many countries are looking forward to for a corruption free government. E-Government is one-way communication protocol whereas E-Governance is two-way communication protocol. The essence of E-Governance is to reach the beneficiary and ensure that the services intended to reach the desired individual has been met with. There should 
be an auto-response system to support the essence of E-governance, whereby the Government realizes the efficacy of its governance. E-governance is by the governed, for the governed and of the governed. Establishing the identity of the end beneficiary is a true challenge in all citizen-centric services. Statistical information published by governments and world bodies do not always reveal the facts. Best form of E-governance cuts down on unwanted interference of too many layers while delivering governmental services. It depends on good infrastructural setup with the support of local processes and parameters for governments to reach their citizens or end beneficiaries. Budget for planning, development and growth can be derived from well laid out E-governance systems.

\section{REFERENCES}

[1] Saugata,B., and Masud,R,R.(2007). Implementing $\mathrm{E}$-Governance Using OECD Model(Modified) and Gartner Model (Modified) Upon Agriculture of Bangladesh. IEEE. 1-4244-1551-9/07.

[2] Garson, D.G. (2006). Public Information Technology and E-Governance. Sudbury, MA: Jones and Bartlett Publishers.

[3] Rossel, Pierre, and Matthias Finger, "Conceptualizing e-Governance." Management (2007) :pp- 399-407

[4] M.Alwan \&et.al. "Psychosocial Impact of passive Health status Monitoring on Informal Caregivers and Older Adults living in Independent Senior Housing ", in 2nd Information and Communication Technologies Surabaya, Indonesia 2006, pp-803-813.

[5] JeongGil Ko, \& et.al "Wireless Sensor Networks

[6] For Healthcare" Proceedings of the IEEE | Vol. 98,No. 11,November 2010 pp 1947-1960.

[7] Anjum Razzaque, "A Transcultural Model of E-Governance for the Healthcare IndustryVicto" Journal of Economic Development, Mgmt, IT, Finance and Marketing, 1(1), 193-222, Sept. 2009.

[8] Moshaddique Al Ameen and Kyung-sup Kwak Graduate School of IT and Telecommunications, Inha University, Korea "Social Issues in Wireless Sensor Networks with Healthcare Perspective"The International Arab Journal of Information Technology, Vol. 8, No. 1, January 2011, pp 52-58.

[9] Mihaela Lascu \& Dan Lascu "Graphical Programming based Biomedical Signal Acquisition and Processing " INTERNATIONAL JOURNAL OF
CIRCUITS, SYSTEMS AND SIGNAL PROCESSING , Issue 4, Volume 1, 2007,pp317-326.

[10][9]. Mihaela Lascu \& Dan Lascu“LabVIEW Electrocardiogram Event and Beat Detection" WSEAS TRANSACTIONS on COMPUTER RESEARCH, ISSN: 1991-8755, Issue 1, Volume 3, January 2008,pp-9-18.

[11] Romit Pandey and KS Vijaya Sekhar, "From eGovernance to m-Governance: The way forward " e-Gov - Technological Framework

[12]Vertika Shukla,"Current Status of Egovernance in Healthcare in the Large Hospitals of Bangalore" Thesis paper.

[13]A. Cerpa, J. Elson, D. Estrin, L. Girod, M. Hamilton, and J.Zhao.Habitat monitoring: Application driver for wireless communications technology.In Proc. the Workshop on Data Communications in Latin America and the Caribbean, Apr. 2001.

[14] R. Szewczyk, A. Mainwaring, J. Polastre, and D. Culler. An analysis of a large scale habitat monitoring application. In Proc. Second ACM Conference on Embedded Networked Sensor Systems (SenSys), November 2004.

[15] G. Werner-Allen, J. Johnson, M. Ruiz, J. Lees, and M. Welsh. Monitoring volcanic eruptions with a wireless sensor network. In Proc. Second European Workshop on Wireless Sensor Networks (EWSN'05), January 2005.

[16]C. Intanagonwiwat, R. Govindan, and D. Estrin. Directed diffusion: A scalable and robust communication paradigm for sensor networks. In Proc. International Conference on Mobile Computing and Networking, Aug. 2000.

[17]A.Woo, T. Tong, and D. Culler. Taming the underlying challenges of reliable multihop routing in sensor networks. In Proc. the First ACM Conference on Embedded Networked Sensor Systems (SenSys 2003), November 2003.

[18] M. Maroti, B. Kusy, G. Simon, and A. Ledeczi. The flooding time synchronization protocol. In Proc. SenSys'04, Baltimore, MD, November 2004.

[19] J. Elson, L. Girod, and D. Estrin. Fine-grained network time synchronization using reference broadcasts. In Proc. Fifth Symposium on Operating Systems Design and Implementation (OSDI 2002), Boston, MA, December 2002.

[20] J. Polastre, R. Szewczyk, and D. Culler. Telos: Enabling ultra-low power wireless research. In Proc. Fourth International Conference on Information Processing in Sensor Networks: Special track on Platform Tools and Design 
S. Mohapatra et al. / International Journal of Computer Networks and Communications Security, 1 (4), September 2013

Methods for Network Embedded Sensors (IPSN/SPOTS), April 2005.

[21]B. Lo and G. Z. Yang. Key technical challenges and current implementations of body sensor networks. In Proc. 2nd International Workshop on Body Sensor Networks (BSN 2005), April 2005.

[22] G.-Z. Yang et al. Body Sensor Network Node. http://www.doc.ic.ac.uk/vip/ubimon/bsn_node/ index.html.

[23]E. Shih, V. Bychkovsky, D. Curtis, and J. Guttag. Demo abstract: Continuous, remote medical monitoring. In Proc. Second Annual International Conference on Embedded Networked Sensor Systems, November 2004.

[24]D. Konstantas, V. Jones, R. Bults, and R. Herzog. Mobihealth - innovative 2.5/3g mobile services and applications for healthcare. In Proc. Eleventh IST Mobile and Wireless Telecommunications Summit 2002, Thessaloniki,Greece, June 2002.

[25]E. Dishman. Inventing wellness systems for aging in place. IEEE Computer, 37(5), May 2004.

[26]K. V. Laerhoven, B. P. Lo, J. W. Ng, S. Thiemjarus, R. King, S. Kwan,H.-W. Gellersen, M. Sloman, O. Wells, P. Needham, N. Peters, A. Darzi,C. Toumazou, and G.-Z. Yang. Medical healthcare monitoring with wearable and implantable sensors. In Proc. Sixth International Conference on Ubiquitous Computing, Tokyo, Japan, September 2004.

[27]L. Ohno-Machado et al. SMART: Scalable Medical Alert Response Technology. http://smart.csail.mit.edu/.

[28]D. White et al. AID-N: Advanced Health and Disaster Aid Network. https://secwww.jhuapl.edu/aidn/.

[29] L. Lenert et al. WiiSARD:Wireless Internet Information System for Medical Response in Disasters. https://wiisard.org.

[30]E. Shih, V. Bychkovsky, D. Curtis, and J. Guttag. Demo abstract: Continuous, remote medical monitoring. In Proc. Second Annual International Conference on"Embedded Networked Sensor Systems,” November 2004.

[31]BTing-Chen Ke Kuo-Yu Yang, "A wireless patch-type physiological monitoring microsystem,'IEEE Sensors, EXCO, Daegu, Korea, October 22-25, pp. 1143-1146, 2006.

[32]B.-S. Lin, N.-K. Chou, F.-C. Chong, S.-J. Chen, "RTWPMS: A real-time wireless physiological monitoring system," IEEE Transactions on Information Technology inBiomedicine, vol. 10, pp. 647-656, 2006.
[33] S. Intille. Enabling population-scale physical activity measurement on common mobile phones. NIH GEI project at MIT. Available from: ttp://www.gei.nih.gov/exposurebiology/ program/docs/StephenIntille.pdf, 2007.

[34] S. Kumar. Autosense. NIH GEI project at The University of Memphis. Available from: http://www.cs.memphis.edu/santosh/AutoSens e.html, 2007.

[35]K. Patrick. A tool for geospatial analysis of physical activity: Physical activity location measurement system (palms). NIH GEI project at the University of California, San Diego. Available from: http://www.gei.nih.gov/exposurebiology/progr am/docs/KevinPatrick.pdf, 2007.

[36] M.S. Goodwin, W.F. Velicer, and S.S. Intille. Telemetric monitoring in the behavior sciences. Behavior Research Methods, 2007.

[37]Min Mun, Sasank Reddy, Katie Shilton, Nathan Yau, Jeff Burke,Deborah Estrin, Mark Hansen, Eric Howard, Ruth West, and P'eterBoda. Peir, the personal environmental impact report, as a platform for participatory sensing systems research. In MobiSys '09: Proceedings of the 7 th international conference on Mobile systems, applications, and services, pages 55-68, New York, NY, USA, 2009. ACM.

[38]Deffie-Hellman Rfc. Available online: http://www.ietf.org/rfc/rfc2631.txt (accessed on 20 July 2011).

[39] Meingast, M.; Roosta, T.; Sastry, S. "Security and Privacy Issues with Healthcare Information Technology". In Proceedings of the 28th IEEE EMBS Annual International Conference, New York, NY, USA, 31 August-3 September 2006; pp. 5453-5458.

[40] Bachman JW, The patient computer interviewA neglected tool that aid the Clinician, Mayo Clinic Proc. 2003; 78 : Pages: 67-8.

[41]Blobel B, Nerdberg R and et al, Modelling privilege Management and access control, International Journal of Medical Informatics, 2006,75:597

[42] Bruno von Nirman, Steve brown User experience design guidelines for Tele-care (eHealth) Services, Interactions, Sept 2007, Pages: 36-40.

[43] Community Information Centre Web site http://www.cic.nic.in la last visited 30 Sep'08

[44] Das R K, Dash S S (2007), Telereferal Service of NIC-A Helping hand for the Doctors and Inhabitants ofKBK districts of Orissa, Adopting e-Governance, GIFT Publishing 2007 , Pages: 253-8 
[45]Al-Sakib Khan Pathan1 and et. al "A Framework for Providing E-Services to the Rural Areas using Wireless Ad Hoc and Sensor Networks" IEEE ICNEWS 2006, 2-4 January, Dhaka, Bangladesh, 2006, pp. 282-286.

[46] Khushboo Batra, \& et.al "E- GOVERNANCE IN INDIA "International Journal of Computing \& Business Research ISSN : 2229-6166, Proceedings of 'I-Society 2012' at GKU, Talwandi Sabo Bathinda (Punjab).

[47]S. C. Mahapatraland et.al "Current eGovernance Scenario in Healthcare sector of India

[48]A. S. Lewis and G. Knowles, "Image compression using the 2-D wavelet transform," IEEE Trans. Image Processing, vol. 1, pp. 244-250, Apr. 1992.

[49] M. Antonini, M. Barland, P. Mathieu, and I. Daubechies, "Image coding using the wavelet transform," IEEE Trans. Image Processing, vol. 1, pp. 205-220, Apr. 1992.

[50]M.Shapiro,"Embedded image coding using zerotrees of wavelet coefficients," IEEE Trans.Signal Processing, vol.41,pp.3445-3463, Dec. 1993.

[51]M. L. Hilton, "Compressing still and moving images with wavelets," Multimedia Syst., vol. 2, no. 3, pp. 218-227, 1994.

[52]Z. Xiang, K. Ramchandran, M. T. Orchard, and Y. Q. Zhang, "A comparative study of DCTand wavelet-based image coding," IEEE Trans. Circuits Syst. Video Technol., vol. 9, pp. 692695, Apr. 1999

[53]E. Feig, "A fast scaled DCT algorithm," Proc. SPIE-Image Process. Algorithms Techn., vol. 1244, pp. 2-13, Feb. 1990.

[54]Kennedy.J; Eberhart.R; "Particle Swarm Optimizing" Bur. Of Labor stat. Washington,DC,USA. IEEE, International Conferrence on Nov/Dec 1995.

[55] Grill-Specter, K., Sayres, R., and Ress, D. (2006). "High-resolution imaging reveals highly selective nonface clusters in the fusiform face area." Nature Neu-roscience 9 (9) $1177-1185$

[56] Haxby, J., Gobbini, M., Furey, M., Ishai, A., Schouten, J., and Pietrini, P.(2001)." Distributed and Overlapping Representations of Faces and Objects in Ventral Temporal Cortex Science" 293 2425-2430

[57] LaConte, S., Peltier, S., and Hu, X. (2002). "Real-Time fMRI Using Brain-State Classification Human Brain Mapping "28 1033-1044

[58] S. Bauer, B. Zovko-Cihlar, and M. Grgic, "The influence of impairments from digital compression of video signal on perceived picture quality," in Proc. 3rd Int. Workshop Image and Signal Processing, IWISP'96, Manchester, U.K., 1996, pp. 245-248.

[59]A.Said and W.A.Pearlman, "A new fast and efficient image codec based on set partitioning in hierarchical trees", IEEE Trans. Circuit Syst. Video Technol., vol.6, pp.243250, June 1996 